\title{
Microsporidial stromal keratitis: an uncommon etiology of bilateral simultaneous corneal infection
}

Pragnya R. Donthineni' ${ }^{1}$, Somasheila I. Murthy ${ }^{1}$, Joveeta Joseph ${ }^{2}$, Prashant Garg ${ }^{1}$, Manisha Acharya ${ }^{3}$, Virender Sangwan ${ }^{3}$

'The Cornea Institute, LV Prasad Eye Institute, Kallam Anji Reddy Campus, Hyderabad, India; ${ }^{2}$ Jhaveri Microbiology Centre, LV Prasad Eye Institute, Kallam Anji Reddy Campus, Hyderabad, India; ${ }^{3}$ Shroff's Charity Eye Hospital, Darya Ganj, New Delhi, India

\begin{abstract}
We report three cases of bilateral microsporidial keratitis, which is an unusual presentation. All three patients presented with bilateral, simultaneous, asymmetrical, deep stromal corneal infiltrates with symptoms ranging from 5 to 12 months. Predisposing factors were noted in two of three patients. Corneal scrapings for microbiology and histopathology of corneal tissue revealed microsporidial spores from both eyes of all patients. There was no response to medical therapy and all underwent bilateral corneal transplantation. Case one additionally had recurrences in the graft and underwent repeat keratoplasties and eventually keratoprosthesis. Microsporidial stromal keratitis is a possible cause of keratitis in cases of very long-standing, indolent, culture-negative, deep stromal corneal infiltrates. So far, this infection has been reported as unilateral; however, we report these cases of bilateral infection, which is rare. Corneal transplantation is the preferred line of management due to lack of response to medical therapy.
\end{abstract}

Keywords: bilateral corneal infection, indolent keratitis, microsporidia outcomes, microsporidial stromal keratitis, therapeutic keratoplasty

\section{Introduction}

Microsporidia are opportunistic pathogens and can cause keratoconjunctivitis, ${ }^{1}$ stromal keratitis, ${ }^{2}$ and endophthalmitis. ${ }^{3}$ Stromal keratitis is rare, has an indolent course, and often mimics herpes simplex virus (HSV) or fungal keratitis. While there are several reports on unilateral infection, bilateral simultaneous stromal involvement has not been described before and we present our experience with three such patients. The clinical and demographic details of all three cases are summarized in Table 1.

Correspondence: Somasheila I. Murthy, MD, Head of the Cornea Service, Tej Kohli Cornea Institute, LV Prasad Eye Institute, Kallam Anji Reddy Campus, LV Prasad Marg, Banjara Hills, Hyderabad 500034, Telangana, India.

E-mail: smurthy@lvpei.org 
Table 1. Age, gender distribution, and associated history of the three cases

\begin{tabular}{|c|l|l|l|l|l|l|l|}
\hline Cases & $\begin{array}{l}\text { Age } \\
\text { (years) }\end{array}$ & Sex & $\begin{array}{l}\text { Duration } \\
\text { of } \\
\text { symptoms }\end{array}$ & $\begin{array}{l}\text { Waxing } \\
\text { and } \\
\text { waning of } \\
\text { symptoms }\end{array}$ & $\begin{array}{l}\text { History } \\
\text { of } \\
\text { trauma }\end{array}$ & $\begin{array}{l}\text { Prior } \\
\text { use of } \\
\text { steroids }\end{array}$ & $\begin{array}{l}\text { Initial } \\
\text { working } \\
\text { diagnosis }\end{array}$ \\
\hline $\begin{array}{c}\text { Case 1 } \\
\text { (Both } \\
\text { eyes) }\end{array}$ & 52 & M & 8 months & Yes & No & Yes & $\begin{array}{l}\text { HSV } \\
\text { stromal } \\
\text { keratitis }\end{array}$ \\
\hline $\begin{array}{c}\text { Case 2 } \\
\text { RE }\end{array}$ & 73 & M & 1 year & Yes & Yes & Yes & $\begin{array}{l}\text { HSV } \\
\text { stromal } \\
\text { keratitis }\end{array}$ \\
\hline LE & & 6 months & Yes & No & Yes & $\begin{array}{l}\text { HSV } \\
\text { stromal } \\
\text { keratitis }\end{array}$ \\
\hline $\begin{array}{c}\text { Case 3 } \\
\text { RE }\end{array}$ & 49 & F & 3 months & Yes & No & Yes & $\begin{array}{l}\text { Filamen- } \\
\text { tary } \\
\text { keratitis }\end{array}$ \\
\hline LE & & & 3 months & Yes & No & Yes & $\begin{array}{l}\text { Filamen- } \\
\text { tary } \\
\text { keratitis }\end{array}$ \\
\hline
\end{tabular}

HSV: herpes simplex virus; LE: left eye; RE: right eye

\section{Case reports}

\section{Case 1}

A 47-year-old woman with a 15-year history of rheumatoid arthritis presented with severe dry eye. She was on systemic infliximab infusions, ocular lubricants, punctal plugs, and scleral contact lenses. Clinical examination revealed diffuse, bilateral, elevated filament-like lesions with patchy stromal (Fig. 1A and 1B) infiltration. Corneal scrapings revealed large microsporidial spores on $10 \%$ potassium hydroxide $(\mathrm{KOH})$ mount $+1 \%$ Calcoflur stain (CFW). She was started on chlorhexidine eye drops (0.02\%) Q2 hourly and tablet albendazole 400 mg BID. However, there was rapid worsening over the next few weeks, and she underwent bilateral, sequential therapeutic penetrating keratoplasty (PK) (Fig. 1C and 1D). Histopathology of the corneal buttons showed microsporidial infection. Postoperatively, she went on to develop graft recurrences (Fig. 1E) and had to undergo repeat surgeries bilaterally (three grafts in her right eye [RE] and two in her left eye [LE]). Each of the previous grafts showed persistence of the spores in the stroma on histopathology. Eight months after the last surgery, there was resolution of the 
Donthineni et al.

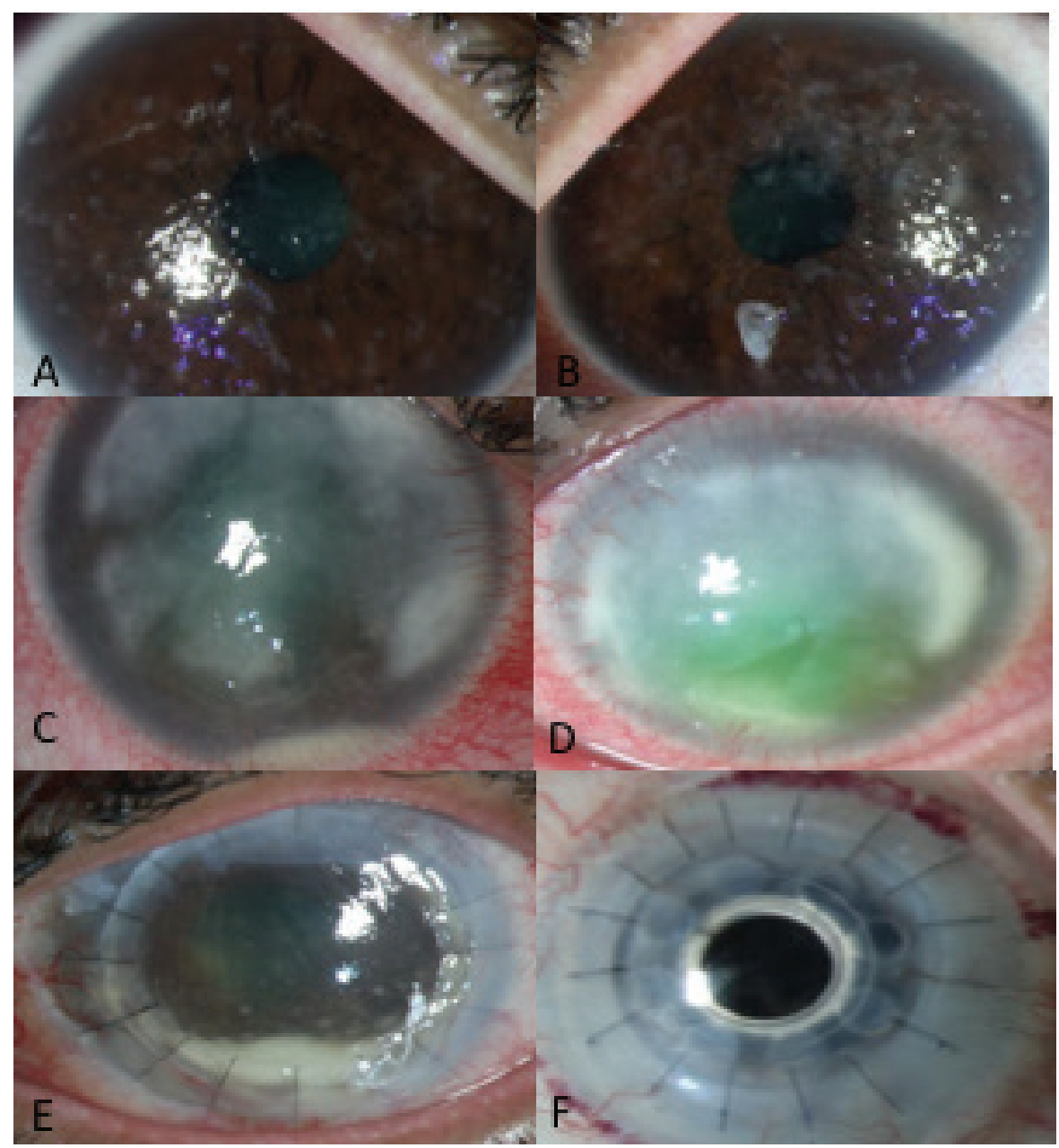

Fig. 1. (A-F) Slit lamp photography images showing the initial presentation of the first patient with diffuse anterior stromal cellularity $(A, B)$ and subsequent worsening with corneal stromal infiltrates $(C, D)$ and post-penetrating keratoplasty image showing recurrence in the left eye (E). (F) Boston type I Kpro in the right eye of the patient.

infection but no improvement in vision; she underwent Boston type I K-Pro bilaterally. Postoperatively, visual acuity improved to 20/30 (Fig. 1F). Subsequently she also developed secondary glaucoma for which glaucoma filtering device surgery was performed bilaterally. At the 5-year follow-up she maintained visual acuities of 20/50 and 20/80 in the right and left eye, respectively. 


\section{Case 2}

A 52-year-old man presented with an 11-month history of waxing and waning symptoms. He recalled a history of foreign body in his RE 10 years prior to presentation. Examination showed bilateral anterior to mid-stromal corneal infiltrates (Fig. 2A and 2B). Corneal scrapings showed microsporidia (Fig. 2C and 2D); he was started on oral albendazole and topical polyhexamethylene biguanide (PHMB) $0.02 \%$ eye drops. Due to rapid worsening, he underwent PK in his RE. Over the next year, the LE showed gradual worsening and PK was performed. Histopathology from both eyes revealed microsporidial spores. The patient maintained clear grafts with $20 / 25$ and $20 / 60$ vision in his RE and LE, respectively at 28 months postoperative.

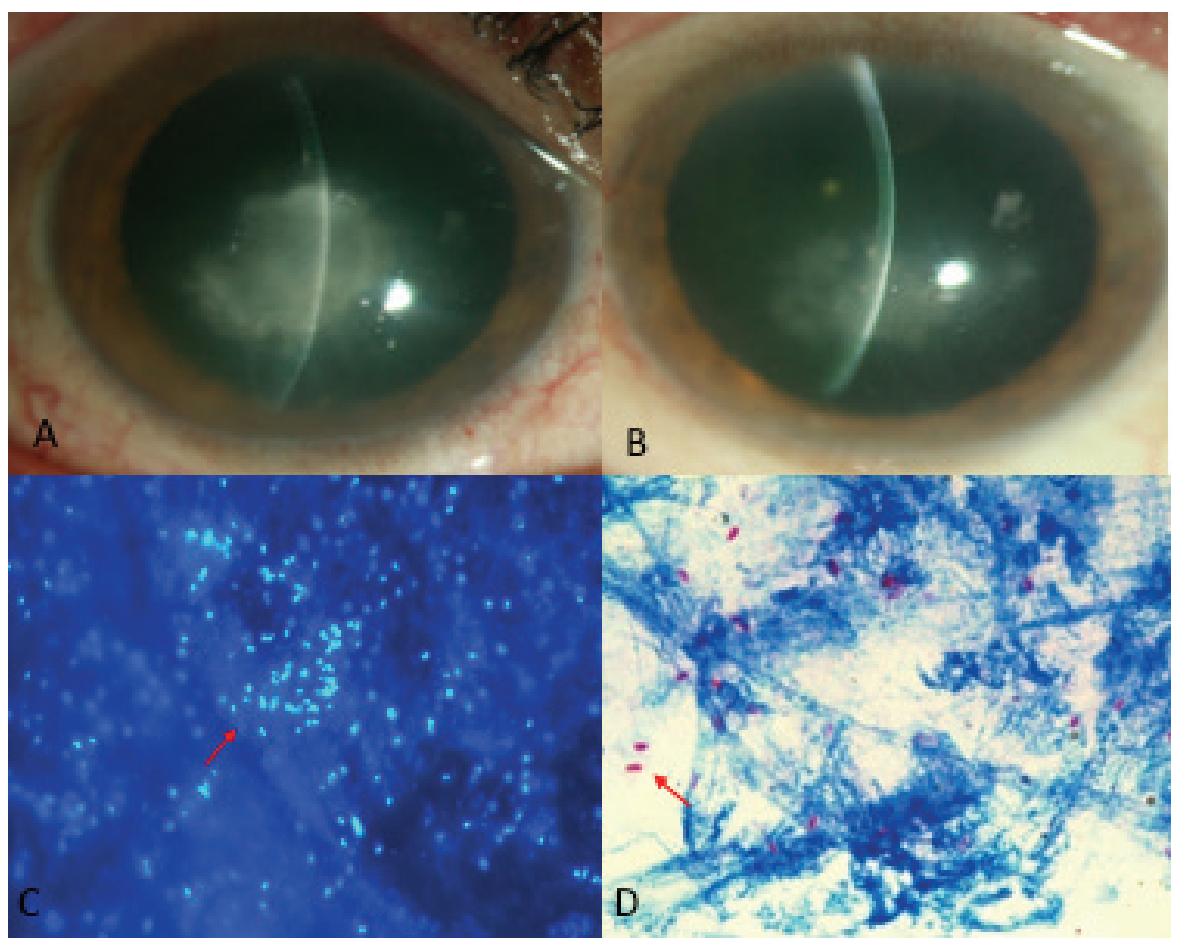

Fig. 2. (A-B) Histopathology photomicrographs of the corneal button revealing oval microsporidial spores in the intralamellar spaces on $40 \times(C)$ and $100 \times(D)$ magnification in the second patient. 


\section{Case 3}

A 73-year-old man presented with bilateral, central, deep, stromal corneal infiltrates (Fig. 3A and 3B). He had undergone cataract surgery in both eyes 3 years prior to presentation. He was on antifungals, topical and oral antivirals, and topical steroids in both eyes. The RE also showed presence of vitreous echoes on B-mode ultrasound scan (Fig. 3C). He was started on topical PHMB $0.02 \%$ and chlorhexidine $0.02 \%$ Q1 hourly. In view of vitreous involvement in his RE, he underwent PK with pars plana vitrectomy (PPV). His LE also showed a similar course and he underwent sequential PK followed by PPV and vitreous biopsy. All ocular specimens showed large microsporidial spores. He did well and had no recurrence at the 1-year postoperative follow-up. Figure 3D shows the RE with a clear and compact graft.

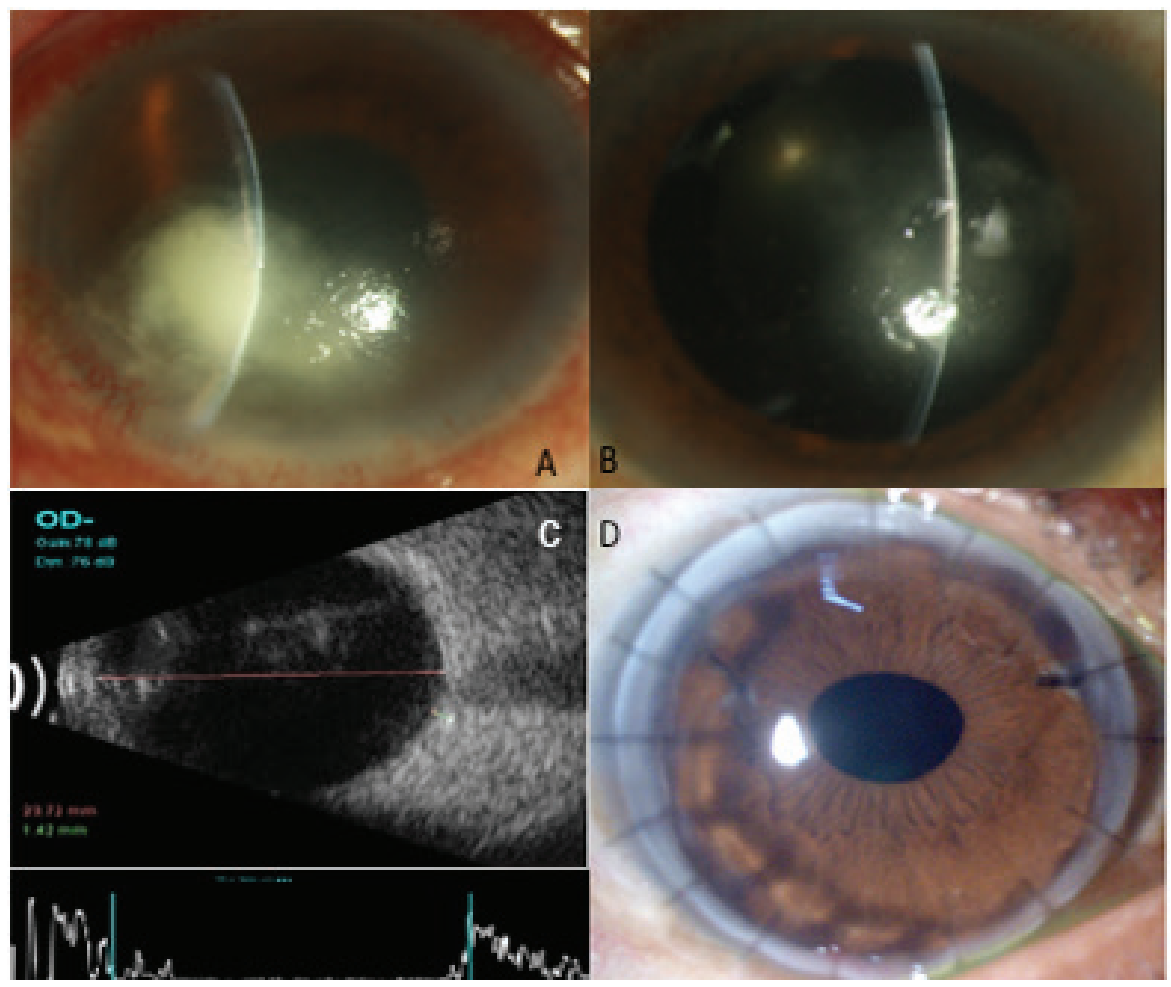

Fig. 3. (A-D) Slit-lamp photography images (A, B) show deep stromal infiltrates in the right and left eye, respectively, of the third patient. Note the echoes in the vitreous cavity on B mode ultrasound in image (C). (D) Post-keratoplasty photograph of the right eye. 


\section{Discussion}

Bilateral simultaneous microbial keratitis is rare, either bacterial if acute or due to contact lenses, ${ }^{4}$ or following bilateral surgery such as refractive surgery or collagen cross-linking. ${ }^{5}$ The commonest causes of indolent bilateral keratitis include HSV stromal keratitis and immune-mediated peripheral ulcerative keratitis. Microsporidia is well recognized as an emerging cause of microbial keratitis, ${ }^{6}$ with a protracted progressive course associated with waxing and waning of symptoms. However, bilateral simultaneous keratitis in the stromal form is rare. It is now established that the disease has a chronic history, with a duration from 8 months to 2 years. ${ }^{3}$ The diagnosis is established by demonstration of spores using gram and $\mathrm{KOH}+\mathrm{CFW}$ stains as well as histopathological specimens. ${ }^{9}$

In our cases we noted simultaneous bilateral presentations. Each case was different, with the first case developing rapid progression and multiple recurrences despite keratoplasty. which could be attributed first to the patient's immunosuppressed status and second to the peripheral corneal involvement. The second case, in contrast, mimicked HSV keratitis, maintained good vision and showed very slow progression, with excellent outcome following keratoplasty. This could be due to better host-immune response. The third case, which was pseudophakic in both eyes, developed endophthalmitis along with keratitis. Stromal keratitis along with endophthalmitis has been reported before but as a unilateral presentation. ${ }^{8}$

The mode of infection is presumed to be feco-oral, following trauma or from animal exposure. ${ }^{9}$ In two of our cases, the mechanism of bilateral infection is intriguing and the mechanism of inoculation is not clear; one case had history of trauma. None had systemic infections, such as respiratory or gastrointestinal infections, which commonly occur due to microsporidia. The first case underwent a comprehensive evaluation by an infectious disease specialist in order to localize the focus of the primary infection and was also on prolonged oral treatment; this was the only patient who had multiple recurrences.

Although there are reports of successful management of microsporidial stromal keratitis with medical therapy, ${ }_{1}^{10}$ based on our experience with these bilateral and other unilateral cases of microsporidia presenting to us, we believe it is important to consider surgical management even in bilateral cases, as medical management does not seem to work. Hence, bilateral microsporidial stromal keratitis is a rare entity but should be suspected in cases with prolonged duration and waxing and waning of symptoms. Altered and recalcitrant clinical course can be expected in immunocompromised patients. 


\section{Acknowledgments}

The authors wish to acknowledge the contribution of the Hyderabad Eye Research Foundation, Hyderabad, India for providing non-financial research resources.

\section{References}

1. Metcalfe TW, Doran RM, Rowlands PL, Currey A, Lacey CJ. Microsporidial keratoconjunctivitis in a patient with AIDS. Br J Ophthalmol. 1992; 76:177-178.

2. Sabhapandit S, Murthy SI, Garg P, Korwar V, Vemuganti GK, Sharma S. Microsporidial Stromal Keratitis: Clinical Features, Unique Diagnostic Criteria, and Treatment Outcomes in a Large Case Series. Cornea. 2016;35(12):1569-1574

3. Yoken J, Forbes B, Maguire AM, Prenner JL, Carpentieri D. Microsporidial endophthalmitis in a patient with acute myelogenous leukemia. Retina. 2002;22(1):123-125.

4. On Annie LH, Ray M. Bilateral simultaneous infective keratitis. Cont Lens Anterior Eye. 2017; 40(4):224-227.

5. Tzamalis A, Romano V, Cheeseman R, Vinciguerra R, Batterbury M, Willoughby C. Bandage contact lens and topical steroids are risk factors for the development of microbial keratitis after epithelium-off CXL. BMJ Open Ophthalmol. 2019;16;4(1)

6. Vemuganti GK, Garg P, Sharma S, Joseph J, Gopinathan U, Singh S. Is microsporidial keratitis an emerging cause of stromal keratitis? A case series study. BMC Ophthalmol. 2005;5:19

7. Joseph J, Sridhar MS, Murthy S, Sharma S. Clinical and microbiological profile of microsporidial keratoconjunctivitis in southern India. Ophthalmology. 2006;113:531-537.

8. Sood AB, Debiec MR, Yeh S, Grossniklaus HE, Randleman JB. Microsporidial stromal keratitis and endophthalmitis in an immunocompetent patient. J Ophthalmic Inflamm Infect. 2016;6(1):30

9. Mathis A, Weber R, Deplazes P. Zoonotic potential of the microsporidia. Clin Microbiol Rev. 2005;18(3):423-45

10. Coca M, Kim J, Shenoy S, Chévez-Barrios P, Kapur M. Microsporidial Stromal Keratitis: Successful Treatment with Topical Voriconazole and Oral Itraconazole. Cureus. 2016 20;8(12):934. 